\title{
Performance of Porous-Venturi Microbubble Generator for Aeration Process
}

\author{
Lathifa Putri Afisna ${ }^{a}$, Wibawa Endra Juwana ${ }^{b}$ Indarto $^{c}$, Deendarlianto ${ }^{d}$, Fellando Martino Nugroho ${ }^{e}$ \\ c,d Department of Mechanical and Industry Engineering, Engineering Faculty, Gadjah Mada University \\ Jl. Grafika No.2, Yogyakarta, 55281, Indonesia. \\ ${ }^{\mathrm{b}}$ Master Program of Mechanical Engineering Gadjah Mada University \\ a Postgraduate Program of Mechanical Engineering Gadjah Mada University \\ eUndergraduate Program of Mechanical Engineering Gadjah Mada University
}

e-mail: lathifa putriafisna@yahoo.com, wibawa.ej@gmail.com, deendarlianto@ugm.ac.id, indarto@ugm.ac.id, fellandomartino1@gmail.com.

\begin{abstract}
Qualified and preserved water is declining due to metal, waste, and hazardous chemicals contamination. Demand on fresh water raises and leads to the efforts on processing waste water with effective and efficient technology. Microbubble generator technology developed lately to result dissolved oxygen for raising microorganisms to decompose waste in waste water. This research used porous-ventury microbubble generator with $30^{\circ}$ inlet angle and $20^{\circ}$ outlet angle, placed in the center of $280 \mathrm{~cm} \times 60 \mathrm{~cm} \times 40 \mathrm{~cm}$ aquarium for experiment. This research aimed to find out bubble distribution and microbubble generator (MBG) performance. Measurement on bubble distribution conducted using Phantom Control Camera. Obtained data analyzed using MATLAB R2016a, while $M B G$ performance measured using pressure transducer. Analysis conducted on variations of gas debit $(0,1 \mathrm{lpm} ; 0,4 \mathrm{lpm}$., and $1 \mathrm{lpm})$ and water debit (30-80 lpm) effects toward performance parameters, such as hydraulic power $\left(L_{w}\right)$ and bubble generating efficiency $\left(\eta_{B}\right)$. Results show that the greatest microbubbles' diameter is 150-500 $\mu \mathrm{m}$, hydraulic power $\left(L_{w}\right)$ increases with the inclining water debit (QL), effect of gas debit variation exert low effect towards $L w$, and declining number of bubble generating efficiency $\left(\eta_{B}\right)$ parameter with the inclining number of the water debit ( $\left.Q_{L}\right)$.
\end{abstract}

Keywords: microbubble generator; ventury; porous; hydraulic power; bubble generating efficiency

\section{INTRODUCTION}

The growth of population and industrial leads to the depletion of water supply quality. It has impact on water pollution caused by industrial and household waste. The polluted water contains metal, waste, and harmful chemicals. Efforts on industrial waste processing is needed to maintain environmental sustainability and business. One of it would be creating wasted water processing technology with affordable building expense and inexpensive operational fee.

Previously developed wasted water processing technique was using biological technique. It is divided into two, aerobe and anaerobe. Aerobe process is waste processing with oxygen. Economically, this technique needs less cost and environmentally friendly. Besides, it has advantage in microorganism growth, where it occurred faster than those in anaerobe process [1]. The microorganism is developed by giving oxygen. Technique to increase oxygen supply is using latest technology called as microbubble generator. It results oxygen to preserve microorganism in waste that moreover, the organism decomposes wasted water. Microbubble generator has simpler construction and better capability in water filtration than other technology [2]. Microbubble defined as gas bubble with 1 micrometer and $1 \mathrm{~mm}$ size. 
Researchers had widely developed microbubble generator to obtain the best design, such as Sadatomi et al who developed spherical body [2] and multi fluid mixture [3] microbubble. Sadatomi conducted complete research on the characteristics of both microbubble generators. Furthermore, Gordicyuk et al [4] also conducted research by using ventury microbubble generator. This research was conducted to know bubble distribution processed by image processing, power consumption, and dissolved oxygen. Other researchers are Ishikawa et al [5] who developed ventury microbubble generator and Tabei et al [6] who conducted experiment on swirl jet microbubble generator. The experiment was conducted by varying nozzle diameter, gas pressure, and gas debit. This experiment aimed to know the characteristics of bubble diameter and distribution of bubble size. The result shows that swirl jet method has simple and effective mechanism to raise microbubble in short time. Each of design has specific characteristic. Therefore, there is needed further depth research on the types of microbubble generator.

This research developed the new type of microbubble generator, porous-ventury, that is not widely applied in processing wasted water. It is the improvement of Baylar's et al works [7]. The research aimed to know the distribution of bubble and microbubble work method including hydraulic power $(L w)$ and bubble generation efficiency $\left(\eta_{\mathrm{B}}\right)$ on variation of clean water debit and gas debit. Result of this research may regarded as alternative to process industrial wasted water in more effective and efficient.

\section{Methodology}

Research was conducted in Mechanical Fluid Laboratory Department of Mechanical and Industry Engineering, Engineering Faculty, University of Gadjah Mada, Yogyakarta. Research scheme illustrated in Figure 2.1. The dimension of experiment aquarium is 280 $\mathrm{cm} \times 60 \mathrm{~cm} \times 40 \mathrm{~cm}$. Water volume in experiment pool is 672 liter by attaching porousventuri microbubble generator. Venturi Microbubble generator with porous pipe used in this experiment consists of four parts, they are inlet, suction air room, porous pipe, and outlet. The microbubble generator has $10 \mathrm{~mm}$ outlet diameter with $30^{\circ}$ inlet angle and $20^{\circ}$ outlet angle as depicted in Figure 2.2.

Inlet area used for water entry point to the center of aquarium. Vacuum pressure occurred in suction air room made air inhaled through porous pipe and mixed with liquid phase. Moreover, formed microbubble will come out through outlet. Range of gas and water debit observed is 0,$1 ; 0,4$ and $1 \mathrm{lpm}$ and $30-80 \mathrm{lpm}$, respectively. Water debit adjusted by changing three phases water pump frequency, while air debit adjusted with flowmeter. This experiment was conducted on atmosphere pressure and room temperature.

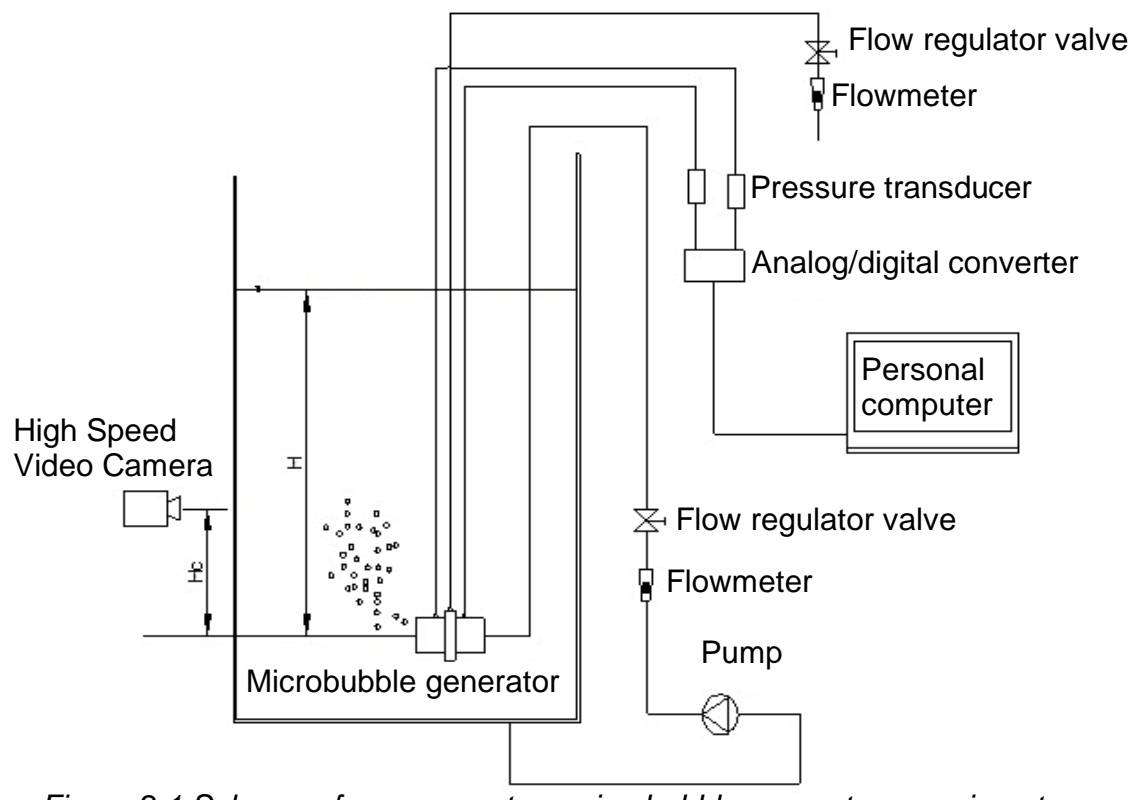

Figure 2.1 Scheme of porous venture microbubble generator experiment

JEMMME | Journal of Energy, Mechanical, Material, and Manufacturing Engineering 


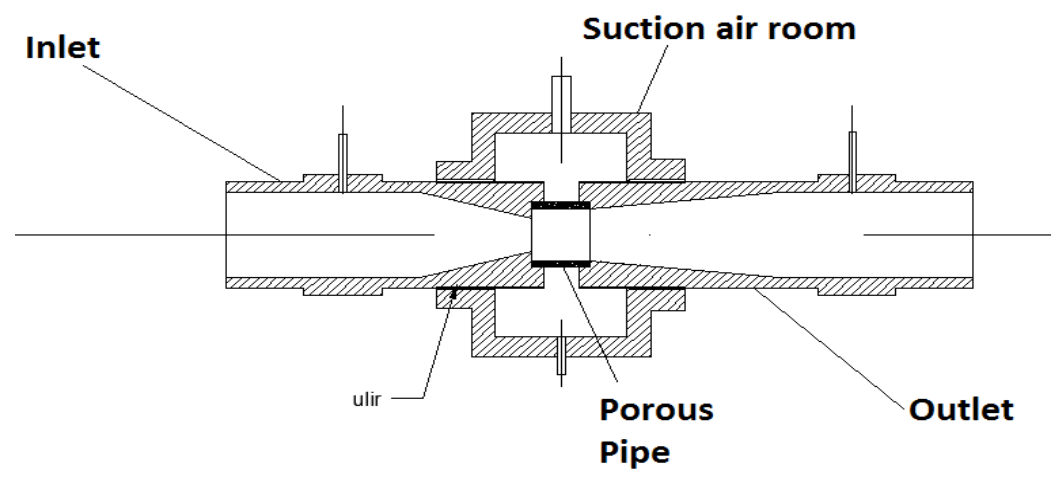

Figure 2.2 Porous venturi microbubble generator and parts

Measurement on microbubble distribution is observed using high-speed video camera Phantom Miro M310. It has $85 \mathrm{~mm}$ focus length and 2,8 lens hole, placed in front of waterfilled aquarium. $50 \mathrm{~W}$ LED lights circuit and white paper added to result uniformity light source. Before capturing, calibration is needed to reach accuracy in observation. Furthermore, microbubble visualization captured and transferred to computer through Phantom Control Camera application. Adjustment for camera speed is determined in 4000 fps to obtain low speed during capturing picture that microbubble clearly photographed. Moreover, data is processed with image processing toolbox MATLAB R2016a to result quantitative data on the distribution of bubble size.

Parameter of inlet and outlet flow pressure is important in measuring microbubble generator (MBG) work method. It is purposed to know hydraulic power $\left(\mathrm{L}_{w}\right)$ and bubble generating efficiency $\left(\eta_{\mathrm{B}}\right)$. Hydraulic power aimed to split air to be microbubble. Meanwhile, bubble generating efficiency indicates ratio between used energy to inhale air and used energy for splitting air to be bubble [2].

Instrument used for measuring MBG work method is pressure transducer. It converts pressure energy to electric energy. The electric is stored to data logger to be processed to calibrated pressure data. This study used pressure transducer with P55D brand and 4N140S4A model number. It has 9-55 VDC power supply and 5VDC output.

Data collection of pressure begins with installing pressure transducer and hose connection to MBG. Before conducting experiment, check valve whether it is in open or close condition. It avoids impact during pump switched on. After all parts installed, water or air debit adjusted based on experiment matrix determined. Furthermore, stored data in data acquisition software processed with MS. Excel. Data processing conducted to calculate hydraulic power $\left(L_{w}\right)$ and bubble generating efficiency $\left(\eta_{B}\right)$ values using formula as follow:

$$
\begin{aligned}
& L_{W}=\left(\mathrm{P}_{1}+\frac{\rho_{\mathrm{L} 1} \mathrm{v}_{\mathrm{L} 1}^{2}}{2}\right) \mathrm{Q}_{\mathrm{L}} \\
& \eta_{\mathrm{B}}=\frac{\rho_{\mathrm{L}} \mathrm{gH} \mathrm{Q}_{\mathrm{G}}}{L_{W}}
\end{aligned}
$$

\section{Result ANd Discussion}

\subsection{Distribution of Bubble size}

The influence of water and gas debit toward distribution of bubble size depicted ini Figure 3.1. In detail, Figure 3.1 shows probability distribution of bubble size in water debit variation when gas debit determined constant $\left(Q_{g}=0,1 \mathrm{lpm}\right)$. Change on water debit will influence bubble size distribution. Result shows that in all combinations, bubble size mostly spread on range of 150-500 $\mu \mathrm{m}$. Hereinafter, probability curve of bubble size distribution in this range increase in line with the increment of water debit. It shows that the number of microbubble in $150-500 \mu \mathrm{m}$ diameter has $Q_{L}=30 \mathrm{lpm}$ as the lowest and the highest is $Q_{L}=$ $80 \mathrm{lpm}$. The lowest water debit, probability curve on bubble size distribution approaches symmetry and tends to have bigger diameter. 


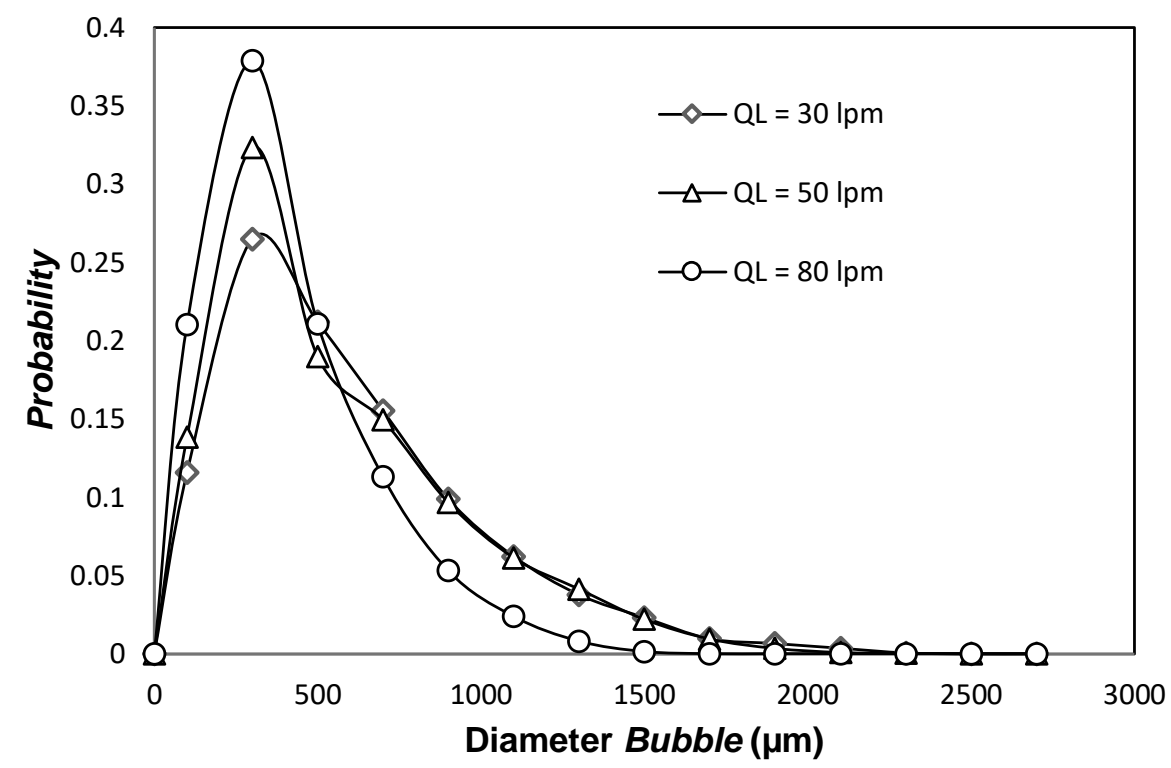

Figure 3.1 Probability on bubble size distribution in variation of water debit and constant gas debit $\left(Q_{g}=0,1 \mathrm{lpm}\right)$.

The influence of gas debit toward bubble size distribution shown in Figure 3.2. The result shows probability of bubble size distribution on water debit $\left(Q_{L}=70 \mathrm{lpm}\right)$ toward variation of gas debit. The increment on gas debit toward constant water debit caused probability curve on distribution of bubble size decrease.

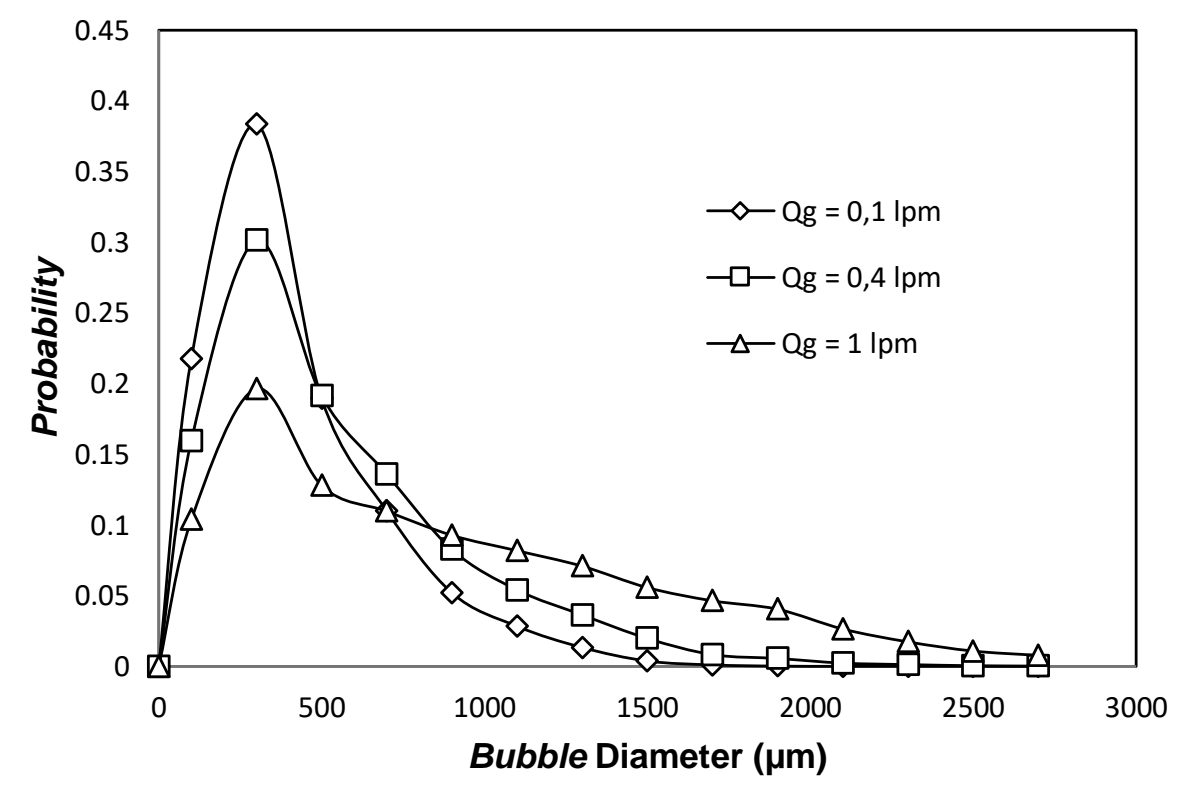

Figure 3.2 Probability of bubble size distribution on variation of constant gas debit and water debit $\left(Q_{L}=70 \mathrm{lpm}\right)$.

Distribution of bubble size is better in proportional symmetry toward air debit increment $\left(Q_{G}\right)$. Occurrence on the phenomenon comes from bubble compounding and shattered as stated by Lau et al [8]. It is caused by shear stress and instability of the bubble. On the 
other hand, turbulence collision rate between two bubbles is comparable with concentration rate. The increment of air-water ratio is expected increasing bubble coalesance rate. Collision rate is comparable with turbulence speed fluctuation and is expected having higher Reynolds number as explained by Gordiychuk et al [5].

The correlation between water debit and average diameter of bubble shows exponential tendency line. The tendency resemble to previous research by Kukizaki et al [9] and Chanjun et al [10]. There are factors influence bubble generation such as momentum, pressure, inertia, and tensile strength. Research by Chanjun et al [10] found that the dominant influence is surface tensile and inertia. Surface stress is comparable with liquid surface tensile and gas inlet diameter. It causes bubble has more defense on its position, while inertia is comparable to bubble volume and liquid speed. It causes bubble flow with the liquid.

In the beginning of microbubble generation, inertia is smaller than surface stress. It causes bubble in its position and bubble volume increase. The phenomenon can explain the influence of water and gas debit in distribution of bubble size. When gas debit increase the inertia is bigger and bubble generation time is shorter that bubble diameter deplete.

\subsection{Hydraulic Power}

\subsubsection{The Influence of Water and Gas Debit toward Hydraulic Power}

Figure 3.3 shows hydraulic power raise in polynomial in line with the increment of water debit $\left(Q_{L}\right)$ when gas debit is constant $\left(Q_{g}=1 \mathrm{lpm}\right)$. Variations on other gas debit also has almost the same inclination. The influence of gas debit change toward hydraulic power is calculated with formulation (1) based on measurement on incoming pressure $\left(P_{1}\right)$ and fluid speed on fluid in inlet microbubble generator $\left(\mathrm{V}^{2} \mathrm{~L}_{1}\right)$. The increment of gas debit on constant water debit has insignificant influence toward hydraulic power as depicted on Figure 3.4. This inclination is almost the same on each variation of water debit. Hydraulic power parameter in this study has maximum combination of $Q_{L}=80 \mathrm{lpm}$ and $Q_{g}=1 \mathrm{lpm}$ by the result of 14,56 Watt, while minimum hydraulic power parameter is $Q_{L}=30 \mathrm{lpm}$ and $\mathrm{Q}_{\mathrm{g}}=0,1 \mathrm{lpm}$ is 1,94 Watt. The debit combination is the lowest one to split air to be microbubble. The smaller hydraulic power needed, the more optimum microbubble resulted.

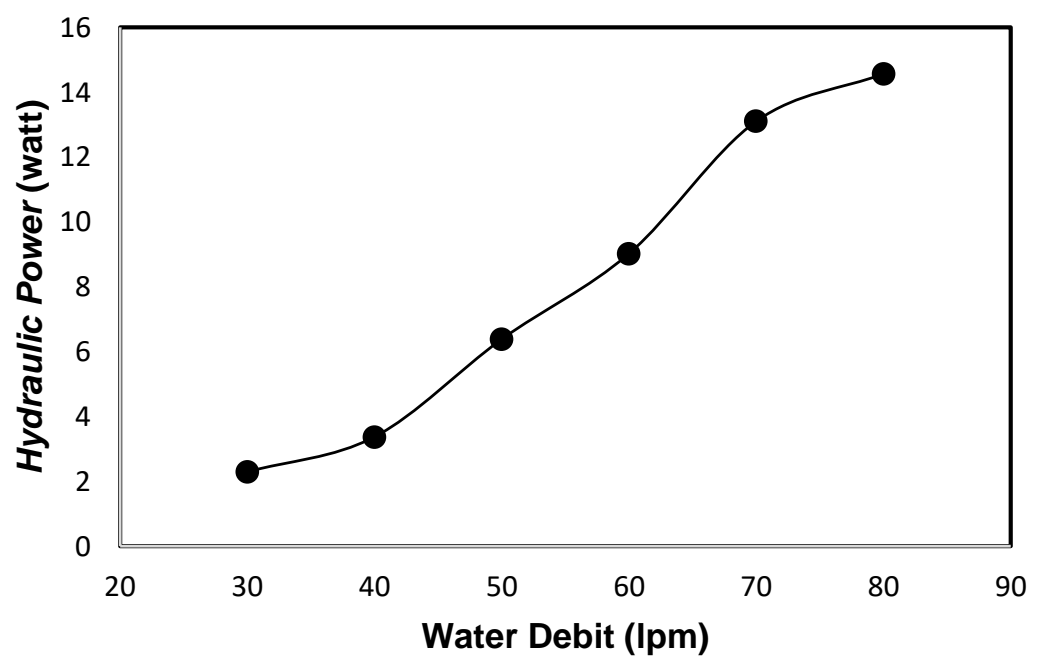

Figure 3.3 Change on hydraulic power toward water debit variation on constant gas debit $\left(Q_{g}=1\right.$ Ipm) 


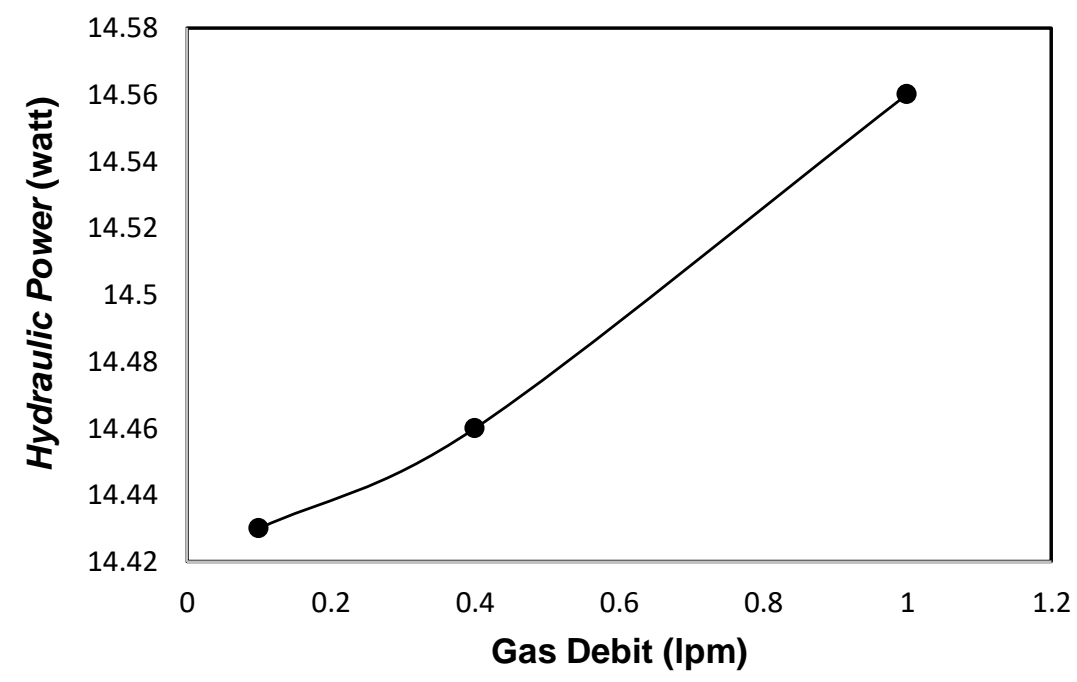

Figure 3.4 Change on hydraulic power toward gas debit variation on constant water debit $\left(Q_{L}=80\right.$ lpm)

\subsubsection{The Influence of Water Debit toward Bubble Generating Efficiency}

Influence of water debit $\left(Q_{g}\right)$ increment toward bubble generating efficiency $\left(\eta_{B}\right)$ is calculated using formulation (2) based on ratio of energy for air suction and rate of hydraulic power. Result shows that $\eta_{B}$ declines with the increment of water debit $\left(Q_{\llcorner}\right)$as depicted on Figure 3.5. On gas debit variation, the highest $\eta_{B}$ is in $Q_{L}=30 \mathrm{lpm}$ on gas debit $0,1 \mathrm{lpm}, 0,4$ $\mathrm{lpm}$, and $1 \mathrm{lpm}$. Furthermore, $\eta_{B}$ declines and reaches steady condition in $Q_{L}=80 \mathrm{lpm}$.

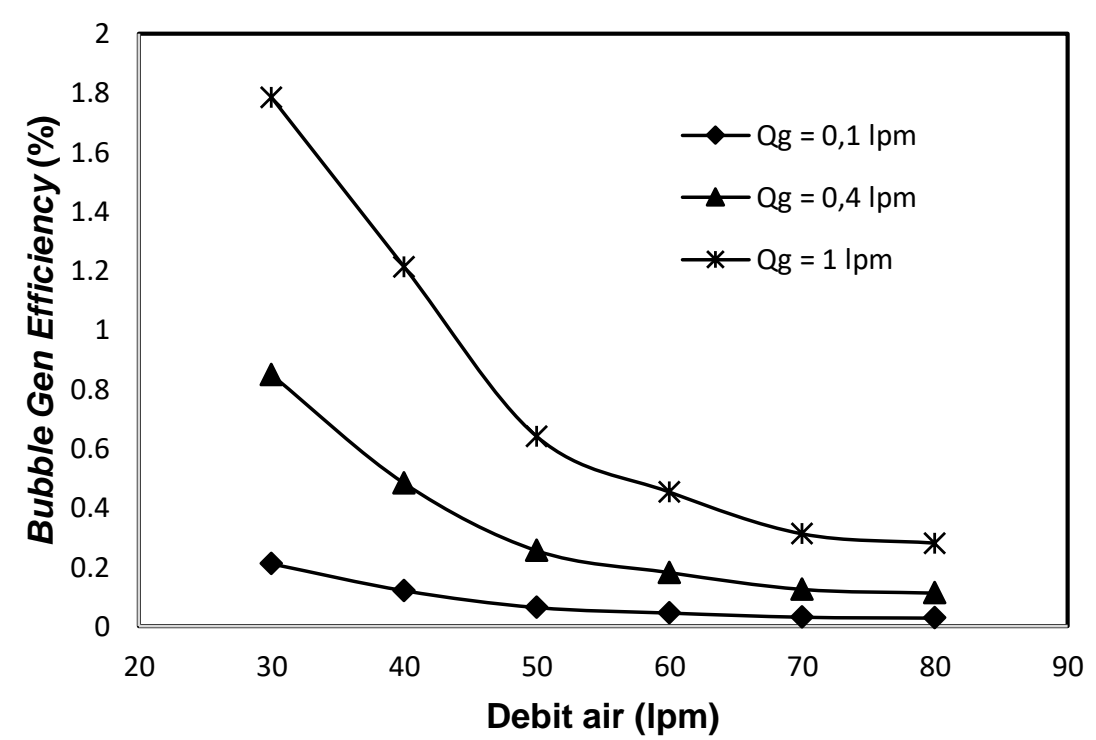

Figure 3.5 Influence of water debit on constant gas debit toward bubble generating efficiency

Based on the graphic of bubble generating efficiency $\left(\eta_{\mathrm{B}}\right)$ the highest average of gas debit variation is in $Q_{g}=1 \mathrm{lpm}$ and the lowest is in $Q_{g}=0,1 \mathrm{lpm}$. If it is compared with spherical body microbubble generator by Sadatomi et al [2], data of this research has low $\eta_{B}$ than samples of the research. Therefore, the low $\eta_{в}$ shows more energy from water to split air to be bubble than to suck air in microbubble generator. 


\subsubsection{The Influence of Gas Debit toward Bubble Generating Efficiency}

The higher gas debit $\left(Q_{g}\right)$, the more increment of bubble generating efficiency $\left(\eta_{B}\right)$ in linear. It is as explained by Sadatomi et al [2] using formulation (2) that stated the bigger $\eta_{\mathrm{B}}$, the bigger energy of water used to suck air. It is caused by energy of water used to split air to be bubble depletes. Increasing $Q_{g}$ leads to more energy needed to suck air.

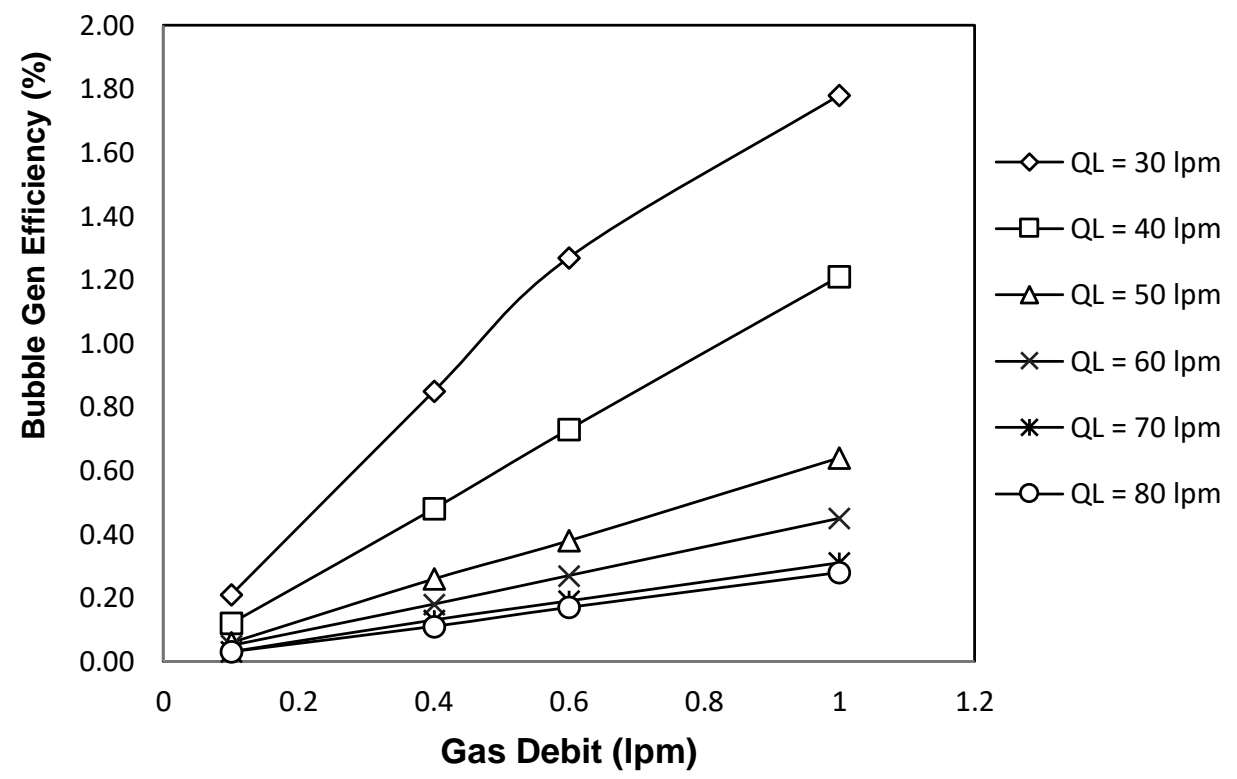

Figure 3.6 The influence of gas debit on constant water debit toward bubble generating efficiency

\section{Conclusion}

Performance of porous-ventury microbubble generator can be analyzed by observing distribution of bubble, hydraulic power and bubble generating efficiency. Result shows that the highest number of microbubble diameter resulted is 150-500 $\mu \mathrm{m}$, hydraulic power (Lw) increased with the increment of water debit $\left(Q_{L}\right)$, the influence of gas debit variation has insignificant effects toward $\mathrm{Lw}$, and bubble generating efficiency $\left(\eta_{\mathrm{B}}\right)$ parameter decreases with the increment of water debit $\left(Q_{L}\right)$. The $\eta_{B}$ is low than samples in previous research. The influence of water and air debit combination can be used to determine the lowest force to split air to be microbubble. The smaller hydraulic power needed, the more optimum microbubble resulted. Further research is expected to measure coefficient of volumetric mass transfer $\left(\mathrm{K}_{\mathrm{La}}\right)$ and reduction of chemical oxygen demand $(\mathrm{COD})$ on artificial waste water application.

\section{Notations}

$L_{w} \quad:$ Hydraulic power (watt)

$\eta_{\mathrm{B}} \quad$ : Bubble generating efficiency (\%)

$P_{l}$ : Compression on microbubble generator $(\mathrm{Pa})$ inlet

$V_{L 1}:$ Water speed on microbubble generator $(\mathrm{m} / \mathrm{s})$ inlet

$Q_{L} \quad:$ Water Debit $\left(\mathrm{m}^{3} / \mathrm{s}\right)$

$Q_{G}:$ Gas Debit $\left(\mathrm{m}^{3} / \mathrm{s}\right)$

$\rho\left\llcorner\quad\right.$ : Water Mass $\left(\mathrm{kg} / \mathrm{m}^{3}\right)$

$g$ : Gravity $\left(\mathrm{m} / \mathrm{s}^{2}\right)$

$H \quad$ : Microbubble generator $(\mathrm{m})$ depth

This work was conducted in research project granted by Direktorat Jenderal Pendidikan Tinggi, The Ministry of Indonesian Education and Culture. Also, sincere appreciation on the support of High Speed Camera Video of Chevron Indonesia and technical support of Wibawa Endra Juwana, Rifki Taufik Alhakim, Fellando Martino, and Valentinus Sabar Parulian. 


\section{REFERENCES}

[1] B.E. Rittman, P.L. Carty, Environmental Biotechnology Principles and Aplication, Boston: Mc Graw Hill.

[2] M. Sadatomi, A. Kawahara, K. Kano, A. Ohtomo, "Performance of New Micro-Bubble Generator With A Spherical Body in Flowing Water Tube", in Experimental Thermal and Fluid Science 29, 615-623, 2005.

[3] M. Sadatomi, A. Kawahara, H. Matsuura, S. Shikatani, "Micro-bubble Generation Rate and Bubble Dissolution Rate into Water by A Simple Multi Fluid Mixer With Orifice and Porous Tube", in Experimental Thermal and Fluid Science 41, 23-30, 2012.

[4] A. Gordiychuk, M. Svanera, S. Benini, P. Poesio, "Size distribution and Sauter mean diameter of micro bubbles for a Venturi type bubble generator", in Experimental Thermal and Fluid Science 70, 51-60, 2016.

[5] M. Ishikawa, K. Irabu, I. Teruya, Nitta, "PIV measurement of concentration flow using microbubble tracer", Proc. The 6th International Symposium on Measurement Techniques for Multiphase Flow, 2009.

[6] K.Tabei, S.Haruyama, S. Yamaguchi, "Study of Micro Bubble Generation by a Swirl Jet", in Journal of Environment and Engineering, 2(1), 172 - 182, 2007.

[7] A. Baylar, F. Ozkan, "Applications of Venturi Principle to Water Aeration Systems", ", in Environmental Fluid Mechanics, vol. 6, 341-357, 2006

[8] Y.M. Lau, N.G. Deen, J.A.M. Kuipers, "Development of an Image Measurement Technique for Size Distribution in Dense Bubble Flow", in Chemical Engineering Science 94, 20-29, 2013.

[9] M. Kukizaki and M. Goto, "Size Control of Nanobubbles generated From ShirasuPorous-Glass (SPG) Membranes", in Journal of Membrane Science 281 (1-2), 386396, 2006.

[10] L. Changjun, L. Bin, T. Shengwei, Z. Haiguang, "A Theoritical Model for The Size Prediction of Single Bubble Formed Under Liquid Cross Flow", in Chinese Journal of Chemical Engineering 18(5), 770-776, 2010. 